\title{
Memory and Space: Towards an Understanding of the Cognitive Map
}

\author{
Daniela Schiller, ${ }^{1}$ Howard Eichenbaum, ${ }^{2}$ Elizabeth A. Buffalo, ${ }^{3}$ Lila Davachi, ${ }^{4}$ David J. Foster, ${ }^{5}$ Stefan Leutgeb, ${ }^{6}$ \\ and Charan Ranganath ${ }^{7}$ \\ ${ }^{1}$ Departments of Psychiatry and Neuroscience, and Friedman Brain Institute, Icahn School of Medicine at Mount Sinai, New York, New York $10029,{ }^{2}$ Center \\ for Memory and Brain, Boston University, Boston, Massachusetts 02215, ${ }^{3}$ Department of Physiology and Biophysics, Washington National Primate \\ Research Center, Seattle, Washington 98195, ${ }^{4}$ Departments of Psychology and Neural Science, New York University, New York, New York 10003, \\ ${ }^{5}$ Department of Neuroscience, The Johns Hopkins University School of Medicine, Baltimore, Maryland 21205, ${ }^{6}$ Neurobiology Section, Division of Biological \\ Sciences, and Kavli Institute for Brain and Mind, University of California, San Diego, La Jolla, California 92093, and ${ }^{7}$ Department of Psychology and Center \\ for Neuroscience, University of California at Davis, Davis, California 95616
}

More than 50 years of research have led to the general agreement that the hippocampus contributes to memory, but there has been a major schism among theories of hippocampal function over this time. Some researchers argue that the hippocampus plays a broad role in episodic and declarative memory, whereas others argue for a specific role in the creation of spatial cognitive maps and navigation. Although both views have merit, neither provides a complete account of hippocampal function. Guided by recent reviews that attempt to bridge between these views, here we suggest that reconciliation can be accomplished by exploring hippocampal function from the perspective of Tolman's (1948) original conception of a cognitive map as organizing experience and guiding behavior across all domains of cognition. We emphasize recent studies in animals and humans showing that hippocampal networks support a broad range of domains of cognitive maps, that these networks organize specific experiences within the contextually relevant map, and that network activity patterns reflect behavior guided through cognitive maps. These results are consistent with a framework that bridges theories of hippocampal function by conceptualizing the hippocampus as organizing incoming information within the context of a multidimensional cognitive map of spatial, temporal, and associational context.

Key words: hippocampus; memory; space; cognitive map; social; navigation

\section{Significance Statement}

Research of hippocampal function is dominated by two major views. The spatial view argues that the hippocampus tracks routes through space, whereas the memory view suggests a broad role in declarative memory. Both views rely on considerable evidence, but neither provides a complete account of hippocampal function. Here we review evidence that, in addition to spatial context, the hippocampus encodes a wide variety of information about temporal and situational context, about the systematic organization of events in abstract space, and about routes through maps of cognition and space. We argue that these findings cross the boundaries of the memory and spatial views and offer new insights into hippocampal function as a system supporting a broad range of cognitive maps.

\section{Introduction}

Historically there have been two major views about the role of the hippocampus. One view argues that the hippocampus is critical for memory: our ability to retrieve both specific experiences and

Received July 9, 2015; revised Aug. 25, 2015; accepted Sept. 2, 2015

Correspondence should be addressed to either of the following: Daniela Schiller, Departments of Psychiatry and Neuroscience, and Friedman Brain Institute, Icahn School of Medicine at Mount Sinai, New York, NY 10029, E-mail: daniela.schiller@mssm.edu; or Howard Eichenbaum, Center for Memory and Brain, Boston University, Boston, MA 02215, E-mail: hbe@bu.edu.

DOI:10.1523/JNEUROSCI.2618-15.2015

Copyright $\odot 2015$ the authors $\quad 0270-6474 / 15 / 3513904-08 \$ 15.00 / 0$ general knowledge gained from them. The other sees the hippocampus as the hub of a navigation system, supporting the brain's capacity to calculate routes for traversing physical space. These views emerged largely through independent lines of research. The link between the hippocampus and declarative memory began with the famous case of patient H.M., who suffered a dense amnesia following removal of the hippocampus and neighboring regions (Scoville and Milner, 1957). Subsequent studies in rats, non-human primates, and human patients have demonstrated dense amnesia following damage to medial temporal lobe structures (Cohen and Squire, 1980; Eichenbaum, 2004). The 
spatial view of hippocampal function was born out of the discovery of "place cells"- hippocampal neurons that fire when an animal moves through specific locations in an environment (O'Keefe and Dostrovsky, 1971). Subsequent studies have identified other types of spatial firing patterns of neurons in the neighboring entorhinal cortex and other areas, supporting the view that the hippocampal system creates maps of physical space and performs navigational computations (Moser et al., 2008; Hartley et al., 2014). Consensus between the memory and spatial views has been difficult because of differences in the species and approaches used-most experiments on memory involve the examination of declarative memory in humans, whereas most experiments on spatial cognition involve maze behavior in animals. Recently, however, several studies have expanded these approaches in humans and animals, leading toward a convergence of the spatial and memory views.

This convergence has been articulated in excellent theoretical reviews that have appeared recently, each proposing to bridge the gap between these disparate views. Buzsáki and Moser (2013), for instance, proposed that memory is a form of navigation in mental space that evolved from, and relies on, the neural algorithms of navigation in the real world. Along the same lines, Milivojevic and Doeller (2013) suggested that memory and spatial navigation both rely on neural machinery that represents space as a mental map of interconnected locations; and Maguire and Mullally (2013) theorized that the primary role of hippocampus is the construction of spatially coherent scenes, which is critical and common to spatial navigation, memory, planning, and imagining. Eichenbaum and Cohen (2014) discussed these views from the perspective of their theory that hippocampus forms a "memory space" where events and episodes are integrated within relational networks (Eichenbaum et al., 1999).

Here we argue that common threads among these reviews are elements of Tolman's (1948) original concept of a cognitive map as a tool for systematically organizing information across multiple domains of life, supporting flexible expression of acquired knowledge in purposeful behavior. The model by O'Keefe and Nadel (1978) introduced the idea that cognitive maps are supported by the hippocampus, but succeeding work has focused on how the hippocampus specifically supports geographical maps as they are used to navigate physical environments. Yet, Tolman's conceptualization provides a framework for research that would reveal a more comprehensive understanding of hippocampal function in cognitive maps that organize memories more generally. Specifically, if Tolman's broader view of cognitive maps is correct, and the hippocampus supports cognitive mapping, by his view, we should be able to demonstrate three fundamental processes in hippocampal function: (1) we should be able to identify cognitive maps that involve memory for domains of knowledge other than physical space; (2) we should be able to specify the organization of memories in meaningful dimensions of the cognitive map in the relevant domain; and (3) we should be able to show that the hippocampal network activity reflects purposeful behavior as movement through the cognitive map. Here we focus on new evidence that supports these predictions. We argue that these studies cross the boundaries of the memory and spatial views and offer new insights into how the hippocampal region represents memories within a multidimensional cognitive map.

\section{Cognitive Maps of Abstract Spaces in the Hippocampus}

\section{Temporal context}

The most straightforward example of an abstract "space" supported by the hippocampus that parallels the organization of physical space is the organization of memories in time. Theories of episodic memory emphasize the idea that memories are represented in a specific temporal as well as spatial context (Tulving, 1983). Consistent with a key role for the hippocampus in temporal organization of episodic memories, numerous studies have revealed that the hippocampus plays a critical role in remembering the order of events in specific experiences (Eichenbaum, 2014). In particular, recent studies in humans using functional neuroimaging (fMRI) have used multivariate analysis approaches to characterize how the human hippocampus distinguishes between and integrates across memories that are temporally organized. These studies have shown that differentiation in hippocampal voxel patterns between two events was related to successful discrimination of the temporal order of events in memories (Ezzyat and Davachi, 2014; Davachi and DuBrow, 2015), whereas statistical learning of temporal associations between two items was associated with increased similarity of hippocampal patterns (Schapiro et al., 2012). In another recent study (Copara et al., 2014), it was reported that, during object recognition, hippocampal activity patterns associated with successful retrieval of the temporal context of the study event differentiated from patterns associated with successful retrieval of the spatial context in which the object had been encountered, suggesting that temporal and spatial representations might be somewhat separable.

In addition, two studies have more directly explored the hippocampal encoding of temporal information during learning or retrieval of sequences of items. Kalm et al. (2013) examined activity patterns during learning of overlapping letter sequences. Their study found that, over learning, hippocampal activity patterns encoded information about specific letter sequences, despite the fact that all of the sequences comprised the same letters. Hsieh et al. (2104) examined hippocampal activity patterns during implicit retrieval of object sequences. Using analyses that allowed them to examine activity elicited during processing of each item, they found that hippocampal voxel patterns were highly correlated across repetitions of the same object in learned sequences, but correlations were context specific, such that presentations of the same object in different sequence contexts were uncorrelated. The results also revealed that participants who showed larger hippocampal sequence representation effects were better able to use sequence knowledge to optimize decisions. The findings from these studies strongly suggest that the hippocampus encodes objects in a context-specific manner, such that different representations will be assigned to successive encounters with the same item in different temporal contexts.

In studies on animals, the robust observation of hippocampal place cells has long been used to advance the idea that the neuronal networks in the hippocampus parse spatial context into representations of locations in space. However, recent studies have shown that, consistent with its key role in temporally organized memory (Fortin et al., 2002), the hippocampus also parses temporally structured experiences into representations of moments in time. In these studies, the location of the animal is held constant while in the midst of performing a memory task. For example, in between traversing paths through a maze, the animal may be forced to run in place on a running wheel or a treadmill. During running in place for specific periods, hippocampal neu- 
rons fire for brief moments in sequences that reliably tile the period of running (Pastalkova et al., 2008; Kraus et al., 2013). The properties of these "time cells" parallel those of place cells, but in the temporal dimension rather than spatial dimensions. In addition, place cell representations change over long periods of time, suggesting a code for when successive events occurred (Mankin et al., 2012). Recent evidence has also distinguished specific aspects of neuronal coding for temporal and spatial context within the hippocampus (Mankin et al., 2015; Wang et al., 2015). Temporal representation by hippocampal neurons is also observed in monkeys (Naya and Suzuki, 2011) and humans (Paz et al., 2010). These observations identify temporal coding by hippocampal neurons as parallel to their coding of space, consistent with the widely held view that episodic memories are embodied as events in spatial-temporal context (Tulving, 1983) and with the idea that cognitive maps span temporal and spatial dimensions of experience.

\section{Visually centered space}

The cognitive map supported by place cells is generally conceived as a Euclidean map from the world-centered (allocentric) view, unlike the perspective from the visual system in person-centered (egocentric) space. If cognitive maps supported by the hippocampus generalize to all relevant dimensions in life experiences, however, one would expect the hippocampal mapping of cognition in egocentric as well as allocentric space. Many studies on amnesia have shown that the human hippocampus is critical to memory for locations on a screen (Voss et al., 2011; Watson et al., 2013), and studies using fMRI have shown that hippocampus activation is associated with memory for the positions of objects on a screen (Piekema et al., 2006; Hannula and Ranganath, 2008; Poch et al., 2011; Libby et al., 2014).

Additional studies of neuronal activity in the hippocampus and neighboring medial entorhinal cortex in monkeys also suggest that cognitive mapping extends to egocentric spatial organization. Hippocampal neuronal activity in monkeys has been strongly associated with an egocentric spatial view, rather than location in allocentric space (Rolls and Xiang, 2006). In addition, it is commonly viewed that the representation of space in the hippocampus depends upon information about allocentric space from the medial entorhinal cortex (Moser et al., 2008; Hartley et al., 2014; but see Brandon et al., 2014). However, recent recording studies in monkeys have revealed the existence of grid cells in the medial entorhinal cortex that fire associated with locations of objects on a screen (Killian et al., 2012), indicating that spatial representation in this system in primates as well as humans applies to visually centered space rather than, or in addition to, location of the body in space.

These findings are consistent with the idea that distinctions in hippocampal representations across rodents and primates may reflect the different ways these species interact with their environment and gain information about the external world. Rodents typically gather information by moving to visit different locations in the environment, sniffing and whisking. By contrast, primates chiefly use eye movements to visually explore an environment, and our visual system allows for inspection of the environment at a distance. Accordingly, a rodent's exploration through space may use the same neural coding mechanisms as a primate's visual exploration. Although the cues used to explore space may differ in primates and rodents, the findings in monkeys suggest that the computations performed by the grid cells are not bound to body orientation or movement in space but, rather, reflect cognitive processing of dynamics for navigating mental space. A clearer understanding of how grid cells are involved in spatial representation and memory in the hippocampus remains a key issue in the field.

\section{Musical and other domains of skill "space"}

Several studies in humans exemplify how hippocampal structure and function vary with experience in modalities that are predominantly governed by dimensions beyond a simple mapping in time or space. Teki et al. (2012) found larger hippocampal gray matter in professional piano tuners navigating a complex soundscape. Piano tuning is a sequential process where the tuning of the current note depends on the previously tuned note. Piano tuners, therefore, use pitch cues and beat rates as landmarks, while navigating well learned "routes" of different tuning algorithms. Teki et al. (2012) found greater gray matter volume in the hippocampus as a function of years of piano tuning, regardless of level of musicality or age, indicating the role of hippocampus in supporting experience-dependent mental navigation within conceptual sound scenes. Other studies further exemplify variation in hippocampal structure and function with experience in additional dimensions including aural skill learning in music academy students (Herdener et al., 2010).

These studies parallel the work of Maguire and colleagues (Maguire et al., 2000; Woollett and Maguire, 2012), who have shown that the hippocampus is larger in London taxi drivers who develop "the knowledge" of the layout of London and can use this knowledge to navigate that geographical space, as well as other work showing structural changes in the hippocampus associated with learning for medical examination in medical students (Draganski et al., 2006). Although these studies do not inform us about the specific computations that the hippocampus performs, they nevertheless indicate that extensive acquisition of abstract knowledge in many domains involves structural changes in hippocampal gray matter.

\section{Social space}

Tavares et al. (2015) revealed that cognitive maps in the human hippocampus extend to social space. Similar to physical space, social space incorporates a number of continuous dimensions, such as power (hierarchy, dominancy, etc.) and affiliation (intimacy, warmth, etc.), which indicate social "distance." Tavares et al. (2015) examined whether the hippocampus maps social space using a geometric model that quantified the dynamic response pattern of people interacting with fictional characters in an abstract two-dimensional social space framed by power and affiliation. Specifically, these authors used a social role-playing game in which participants imagined they had arrived to a new town where they had to find a job and a place to live by interacting with the town's people during fMRI. The participants' choices during the interactions positioned the game characters along the dimensions of power and affiliation. The results showed that hippocampal activation tracked a vector metric, indicating the locations of the characters in social space relative to the participant. Furthermore, hippocampal tracking of the relationship trajectories was stronger in participants who reported better social skills, as though tracking the outcome of social encounters with high fidelity promotes adaptive social behavior in real-world encounters. These findings suggest that the hippocampus supports social "navigation" with a representation of a social cognitive map.

\section{Associational space}

Additional studies in both animals and humans have shown that the hippocampus is necessary for the ability to link and organize 
memories that are associated by shared elements (Bunsey and Eichenbaum, 1996; Zeithamova et al. 2012) or form a hierarchical organization (Dusek and Eichenbaum, 1997; Heckers et al., 2004), suggesting a fundamental function of the hippocampus in associating memories across arbitrary dimensions. For example, a recent study (Zeithamova et al., 2012) examined peoples' ability to learn overlapping association $(\mathrm{AB}$ and $\mathrm{BC})$ and subsequently infer novel relationships based on prior experience (A related to C). Using fMRI, Zeithamova et al. (2012) identified patterns of hippocampal activation during an event overlapping with previous experience that related to successful inference, suggesting a unique role in rapid integration of indirectly related events. Notably, these organizations do not rely on spatial and temporal dimensions, expanding the range of cognitive maps to entirely abstract dimensions of association.

\section{Hippocampal Organization of Events in Multiple Dimensions}

Beyond a general role in cognitive mapping in nonspatial as well as spatial dimensions, if Tolman's view of cognitive mapping is correct, we should be able to identify the precise organization of related memories within the relevant cognitive map. Recent studies have indeed shown that memories are represented within specific spatial contexts and the relevant spatial and nonspatial dimensions of experience organize related memories.

\section{The hippocampus maps memories for objects and events in spatial context}

Numerous studies using fMRI have shown that the human hippocampus is involved in memory for specific locations where particular objects were experienced (for review, see Davachi, 2006; Diana et al., 2007; Eichenbaum et al., 2007). In addition, recent work has demonstrated that, in a working memory task, maintenance of hippocampal activity patterns during encoding of specific object-location associations predicted successful retention of these associations across a delay (Libby et al., 2014). In addition, several studies have shown that hippocampal activity patterns also carry information about nonspatial contextual variables, including task context (Aly and Turk-Browne, 2015) and temporal context (Naya and Suzuki, 2011). Collectively, these findings suggest that the hippocampus plays a highly specific role in episodic memory by forming context-dependent representations that link temporally contiguous, but featurally distinct inputs (Hannula et al., 2013; Copara et al., 2014; Libby et al., 2014).

Parallel single-neuron recordings in animals have shown that hippocampal neurons fire as animals study specific objects in particular places in a spatial environment, including tones (Moita et al., 2003; Itskov et al., 2012), tactile cues, (Itskov et al., 2011), odors (Komorowski et al., 2009), and complex objects (Manns and Eichenbaum, 2009). As animals learn the significance of these objects, hippocampal neurons begin as place cells, but their firing becomes modulated by specific objects in their place fields (Moita et al., 2003; Komorowski et al., 2009). Recordings of single neurons in human epilepsy patients converge with these findings, revealing that hippocampal place cells show enhanced activity during recognition of objects that had been previously encountered in the cells' place fields (Miller et al., 2013), and that hippocampal cells can encode the combination of specific objects and the places with which they are associated (Ison et al., 2015).

\section{The hippocampus organizes related memories in schemas}

In addition to encoding specific events in spatial and nonspatial context, recent evidence indicates that the hippocampus supports the capacity to create and modify "schemas," networks of knowledge that integrate and organize multiple related memories in both humans and animals. For example, in a study by Tse et al. (2007), rats were trained to find specific objects at particular locations within an environment and found that the rats readily incorporated the locations of new specific objects within the established spatial organization of previously learned objects. Both new learning and rapid consolidation of new memories within an existing schema were hippocampal dependent. Parallel fMRI studies in humans have shown hippocampal activation associated with linking specific associations via common elements and consequent insight about indirectly related associations, including associations of events by a common spatial context (Milivojevic et al. 2015) and/or by common nonspatial elements (Heckers et al., 2004; Zeithamova et al. 2012). Similarly, as introduced above, the hippocampus is critical to linking specific object associations and guiding inferences between indirectly related elements in animals (Bunsey and Eichenbaum, 1996; Dusek and Eichenbaum, 1997).

Furthermore, recent studies on population coding by hippocampal neurons indicate that hippocampal neural ensembles represent a highly systematic organization of spatial and nonspatial stimulus dimensions by which specific memories are associated (McKenzie et al., 2014). In this study, rats learned a large number of reward associations of multiple objects experienced in different locations and spatial contexts. Population analyses revealed a hierarchical organization of these memories in the hippocampus, wherein objects with similar reward associations were most closely linked and separated from objects in the same locations but different reward associations, locations where the same events occurred were linked within spatial contexts, and events with opposite reward associations were strongly separated across contexts. This schematic organization suggests that the hippocampus creates a systematic network organization that mirrors the spatial and nonspatial associations that can guide choice behavior and associations between memories experienced at different times.

\section{Map scaling and resolution along the anterior-posterior hippocampal axis}

If indeed a fundamental function of the hippocampus is to organize memories across many dimensions, then it may be expected that the hippocampal map is organized not only by specific dimensions that are relevant to the particular situation, but also by meta-dimensions that reflect organization of any domain of memories. Recent evidence suggests that such a meta-dimension may be the resolution of detail in memories.

In spatial cognitive maps, the resolution of detail is likely reflected in the size of place fields. Indeed, in rodents, the size of place cells firing fields increases along the dorsal-to-ventral axis of the hippocampus such that the dorsal hippocampus represents shorter spatial and temporal scales, whereas the ventral hippocampus represents the longer scales (Kjelstrup et al., 2008; Strange et al., 2014). In humans, some evidence indicates that the posterior hippocampus (the human analog of the rodent dorsal hippocampus) encodes fine-grained spatial representations, whereas the anterior hippocampus (analogous to the rodent ventral hippocampus) represents large-scale spatial context (Nadel et al., 2013). The role of resolution of spatial context in memory was 
recently revealed in a study that identified a prevalence of neurons in the rodent dorsal hippocampus that fired associated with high resolution for particular objects in specific places compared with a prevalence of neurons in the ventral hippocampus that generalized across objects and locations within a spatially and meaningfully distinct context and discriminated between events in different contexts (Komorowski et al., 2013).

This organizational principle may apply to hierarchical mnemonic representation such that small-scale memory segments (specific events) and larger-scale concepts (which are abstracted from specific episodes, such as specific objects, individuals, locations, actions, etc.) are organized along the hippocampal longitudinal axis, where a similar temporal resolution gradient may also be found (for theoretical discussions, see Fanselow and Dong, 2010; Ranganath and Ritchey, 2012; Milivojevic and Doeller, 2013; Poppenk et al., 2013). Consistent with these ideas, a recent study (Nielson et al., 2015) revealed representations of the spatial and temporal dimensions of real-life remembered experiences in the left anterior hippocampus. Specifically, the participants wore smart phones with a life-logging software and global positioning system that captured images, coordinates, and timestamps, while navigating their environment for 2 weeks. The results showed spatiotemporal organization for distances between $100 \mathrm{~m}$ and $30 \mathrm{~km}$ and for times between $15 \mathrm{~h}$ and 1 month. Activity in the anterior hippocampus correlated with spatial distance, temporal distance, and their correlation. These results complement previous studies that established the involvement of the human posterior hippocampus in memory for shorter spatial distance (Hirshhorn et al., 2012; Poppenk et al., 2013), and studies showing hippocampal temporal representation in smaller scales (Manns et al., 2007; Barnett et al., 2014; Ezzyat and Davachi, 2014). Together, these studies support the view of hippocampus as a systematic organization tool for memories according to spatiotemporal dimensional scales.

\section{Hippocampal Navigation via Memory for Paths through the Cognitive Map}

A key tenet in Tolman's view on cognitive maps is that they support expectancies of events and planning of routes to obtain those expectancies. Based on this property of cognitive maps, hippocampal neurons should reflect the overall trajectory of movement through space and not merely current location, both during the execution of routes through space and during planning of routes to be taken. There is now compelling evidence of both of these phenomena.

\section{Hippocampal networks represent spatiotemporal sequences of memories}

The existence of hippocampal place cells has long been used to advance the idea that the hippocampus represents spatial context, but it has become clear that these cells do not solely signal one's location within a static Euclidean coordinate map of geographical space. One key insight has come from studies examining the sequential firing characteristics of place cells in rats performing maze tasks. In these experiments rats traverse a common segment of alternate paths through a maze, for which one can distinguish between neurons whose activity reflects solely the location of the animal in the environment regardless of current path, as expected if the cell's activity only reflects "place," and neurons whose activity reflects the animal's location within a particular path differently from other paths, as expected if the cell's activity reflects a sequential element of the memory within each distinct path.
Consistent with the latter expectancy, several studies have now shown that, when rats traverse a segment of a maze that is common to multiple paths, a distinct place cell sequence is activated depending on which path the animal is pursuing (Frank et al., 2000; Wood et al., 2000, Shapiro et al., 2006, Ainge et al., 2007). Furthermore, when place cells in the normal sequence fire less or not at all, the animals make errors (Robitsek et al. 2013). These observations show that temporal organization is not merely a reflection of moving through locations that happen to be in a particular order but, rather, that the spatial representations are actively organized by their temporal sequence into a representation of a particular spatial memory.

\section{Offline reactivation of hippocampal firing sequences reflects learning and subsequent expressions of memory}

Hippocampal firing sequences that correspond to a previously traversed path can also be "replayed" during sleep and offline rest, further extending the link between temporal and spatial coding in the hippocampus. In these studies, initial recordings of place cells are taken as rats repeatedly traverse a consistent path through an environment. Then, during subsequent sleep or brief periods when the animal is not moving, recordings are again taken and the firing patterns are analyzed to determine the extent to which cells that previously fired in the order corresponding to the sequence of locations also fire in the same order when the rat is asleep or occupies a location far from the cells' place fields. These experiments have revealed that place cell sequences are replayed during sleep and quiet wakefulness, and do so $\sim 20$-fold faster than the actual experience (for review, see Carr et al., 2011).

Further studies suggest that replay does not solely reflect rote reactivation of traversed paths. For example, replays of place cell sequences that end in a reward often occur in reverse order, consistent with the possibility of reinforcement learning mechanisms building the place cell sequences (Foster and Wilson, 2006). Also, replays can involve concatenations of individually experienced behaviors into novel trajectories (Gupta et al., 2010). Furthermore, replays occur when rats are at a choice point in a maze, performing the kind of "vicarious trial and error" Tolman envisioned occurs during purposeful planning (Johnson and Redish, 2007). Similarly, during open field foraging, replays can reflect a novel sequence of places that an animal is about to traverse on the way to a remembered goal location (Pfeiffer and Foster, 2013). In humans, fMRI studies indicate that the hippocampus maximally activated when subjects were planning new routes at the outset of intermediate choice points in a route (Spiers and Maguire, 2006). These findings resemble the kinds of constructive memory retrieval processes that can be used to imagine future scenarios (Hassabis et al., 2007; Addis et al., 2011).

Until recently, the link between replay and memory was speculative. Recent work, however, has shown that disruption of replay events as animals are learning a maze impairs subsequent memory (Girardeau et al., 2009; Ego-Stengel and Wilson, 2010; Jadhav et al., 2012; Nokia et al., 2012). Furthermore, extrinsic activation of neural reward signals (via medial forebrain stimulation) during offline replay resulted in development of a subsequent preference for the reactivated spatial location (de Lavilléon et al., 2015). These observations suggest that replay events play a causal role in spatial memory.

Studies in humans have revealed parallels to the kinds of offline reactivation events that have been observed in rodents. For instance, post-learning changes in hippocampal func- 
tional connectivity have been shown to correlate with individual differences in memory (Tambini et al., 2010). Using multivariate analyses of fMRI data, studies have found evidence for offline reactivation of recently learned information in the entorhinal and retrosplenial cortex (Staresina et al., 2013) and in visual cortical areas (Deuker et al., 2013), although hippocampal activation has not been reported. Some preliminary evidence, however, suggests that reactivation in the hippocampus occurs for contexts that were associated with reward, and the degree of reactivation predicts subsequent memory for items learned in that context (M. J. Gruber, M. Ritchey, S. F. Wang, M. K. Doss, and C. Ranganath, unpublished observation).

\section{Conclusions and Going Forward}

A recent perspective asked whether we can reconcile the memory and spatial views of hippocampal function (Eichenbaum and Cohen, 2014). Here, our brief review highlights considerable evidence that supports reconciliation of these views by adoption of the perspective of cognitive maps as originally conceived by Tolman (1948). Even though his experiments were focused on maze learning, Tolman conceived of cognitive maps as extending generally to mapping life's experiences in any behaviorally relevant domain. He conceived the function of these maps as organizing specific events in systematic fashion appropriate to the dimensions of the relevant context, and he argued strongly that the function of cognitive maps is to support expectancies and planning of behavior to obtain sought goals. The experiments discussed here support the idea that the hippocampal function embodies each of these properties, showing that, in addition to spatial context, the hippocampus encodes a wide variety of information about temporal and situational context, that it creates a systematic organization of information about objects in relation to the spatiotemporal context in which they were encountered, and that hippocampal network activity reflects the planning and execution of behavioral sequences that lead to goals. These recent observations suggest that our understanding of how the hippocampus supports memory and navigation may best be advanced by continued research on mechanisms of Tolman's cognitive maps across domains of memory.

\section{References}

Addis DR, Cheng T, Roberts RP, Schacter DL (2011) Hippocampal contributions to the episodic simulation of specific and general future events. Hippocampus 21:1045-1052. CrossRef Medline

Ainge JA, Tamosiunaite M, Woergoetter F, Dudchenko PA (2007) Hippocampal CAl place cells encode intended destination on a maze with multiple choice points. J Neurosci 27:9769-9779. CrossRef Medline

Aly M, Turk-Browne NB (2015) Attention stabilizes representations in the human hippocampus. Cereb Cortex pii:bhv041. CrossRef Medline

Barnett AJ, O’Neil EB, Watson HC, Lee AC (2014) The human hippocampus is sensitive to the durations of events and intervals within a sequence. Neuropsychologia 64C:1-12. CrossRef Medline

Brandon MP, Koenig J, Leutgeb JK, Leutgeb S (2014) New and distinct hippocampal place codes are generated in a new environment during septal inactivation. Neuron 82:789-796. CrossRef Medline

Bunsey M, Eichenbaum H (1996) Conservation of hippocampal memory function in rats and humans. Nature 379:255-257. CrossRef Medline

Buzsáki G, Moser EI (2013) Memory, navigation and theta rhythm in the hippocampal-entorhinal system. Nat Neurosci 16:130-138. CrossRef Medline

Carr MF, Jadhav SP, Frank LM (2011) Hippocampal replay in the awake state: a potential substrate for memory consolidation and retrieval. Nat Neurosci 14:147-153. CrossRef Medline

Cohen NJ, Squire LR (1980) Preserved learning and retention of pattern- analyzing skill in amnesia: dissociation of knowing how and knowing that. Science 210:207-210. CrossRef Medline

Copara MS, Hassan AS, Kyle CT, Libby LA, Ranganath C, Ekstrom AD (2014) Complementary roles of human hippocampal subregions during retrieval of spatiotemporal context. J Neurosci 34:6834-6842. CrossRef Medline

Davachi L (2006) Item, context and relational episodic encoding in humans. Curr Opin Neurobiol 16:693-700. CrossRef Medline

Davachi L, DuBrow S (2015) How the hippocampus preserves order: the role of prediction and context. Trends Cogn Sci 19:92-99. CrossRef Medline

de Lavilléon G, Lacroix MM, Rondi-Reig L, Benchenane K (2015) Explicit memory creation during sleep demonstrates a causal role of place cells in navigation. Nat Neurosci 18:493-495. CrossRef Medline

Deuker L, Olligs J, Fell J, Kranz TA, Mormann F, Montag C, Reuter M, Elger CE, Axmacher N (2013) Memory consolidation by replay of stimulus-specific neural activity. J Neurosci 33:19373-19383. CrossRef Medline

Diana RA, Yonelinas AP, Ranganath C (2008) High-resolution multi-voxel pattern analysis of category selectivity in the medial temporal lobes. Hippocampus 18:536-541. CrossRef Medline

Draganski B, Gaser C, Kempermann G, Kuhn HG, Winkler J, Büchel C, May A (2006) Temporal and spatial dynamics of brain structure changes during extensive learning. J Neurosci 26:6314-6317. CrossRef Medline

Dusek JA, Eichenbaum H (1997) The hippocampus and memory for orderly stimulus relations. Proc Natl Acad Sci U S A 94:7109-7114. CrossRef Medline

Ego-Stengel V, Wilson MA (2010) Disruption of ripple-associated hippocampal activity during rest impairs spatial learning in the rat. Hippocampus 20:1-10. CrossRef Medline

Eichenbaum H (2004) Hippocampus: cognitive processes and neural representations that underlie declarative memory. Neuron 44:109-120. CrossRef Medline

Eichenbaum H (2014) Time cells in the hippocampus: a new dimension for mapping memories. Nat Rev Neurosci 15:732-744. CrossRef Medline

Eichenbaum H, Cohen NJ (2014) Can we reconcile the declarative memory and spatial navigation views on hippocampal function? Neuron 83:764770. CrossRef

Eichenbaum H, Dudchenko P, Wood E, Shapiro M, Tanila H (1999) The hippocampus, memory, and place cells: is it spatial memory or a memory space? Neuron 23:209-226. CrossRef Medline

Eichenbaum H, Yonelinas AP, Ranganath C (2007) The medial temporal lobe and recognition memory. Annu Rev Neurosci 30:123-152. CrossRef Medline

Ezzyat Y, Davachi L (2014) Similarity breeds proximity: pattern similarity within and across contexts is related to later mnemonic judgments of temporal proximity. Neuron 81:1179-1189. CrossRef Medline

Fanselow MS, Dong HW (2010) Are the dorsal and ventral hippocampus functionally distinct structures? Neuron 65:7-19. CrossRef Medline

Fortin NJ, Agster KL, Eichenbaum HB (2002) Critical role of the hippocampus in memory for sequences of events. Nat Neurosci 5:458-462. CrossRef Medline

Foster DJ, Wilson MA (2006) Reverse replay of behavioural sequences in hippocampal place cells during the awake state. Nature 440:680-683. CrossRef Medline

Frank LM, Brown EN, Wilson M (2000) Trajectory encoding in the hippocampus and entorhinal cortex. Neuron 27:169-178. CrossRef Medline

Girardeau G, Benchenane K, Wiener SI, Buzsáki G, Zugaro MB (2009) Selective suppression of hippocampal ripples impairs spatial memory. Nat Neurosci 12:1222-1223. CrossRef Medline

Gupta AS, van der Meer MA, Touretzky DS, Redish AD (2010) Hippocampal replay is not a simple function of experience. Neuron 65:695-705. CrossRef Medline

Hannula DE, Ranganath C (2008) Medial temporal lobe activity predicts successful relational memory binding. J Neurosci 28:116-124. CrossRef Medline

Hannula DE, Libby LA, Yonelinas AP, Ranganath C (2013) Medial temporal lobe contributions to cued retrieval of items and contexts. Neuropsychologia 51:2322-2332. CrossRef Medline

Hartley T, Lever C, Burgess N, O'Keefe J (2014) Space in the brain: how the hippocampal formation supports spatial cognition. Philos Trans R Soc Lond B Biol Sci 369:20120510. CrossRef Medline

Hassabis D, Kumaran D, Vann SD, Maguire EA (2007) Patients with hippocampal amnesia cannot imagine new experiences. Proc Natl Acad Sci U S A 104:1726-1731. CrossRef Medline 
Heckers S, Zalesak M, Weiss AP, Ditman T, Titone D (2004) Hippocampal activation during transitive inference in humans. Hippocampus 14:153162. CrossRef Medline

Herdener M, Esposito F, di Salle F, Boller C, Hilti CC, Habermeyer B, Scheffler K, Wetzel S, Seifritz E, Cattapan-Ludewig K (2010) Musical training induces functional plasticity in human hippocampus. J Neurosci 30 : 1377-1384. CrossRef Medline

Hirshhorn M, Grady C, Rosenbaum RS, Winocur G, Moscovitch M (2012) Brain regions involved in the retrieval of spatial and episodic details associated with a familiar environment: an fMRI study. Neuropsychologia 50:3094-3106. CrossRef Medline

Hsieh LT, Gruber MJ, Jenkins LJ, Ranganath C (2014) Hippocampal activity patterns carry information about objects in temporal context. Neuron 81:1165-1178. CrossRef Medline

Ison MJ, Quian Quiroga R, Fried I (2015) Rapid encoding of new memories by individual neurons in the human brain. Neuron 87:220-230. CrossRef Medline

Itskov PM, Vinnik E, Diamond ME (2011) Hippocampal representation of touch-guided behavior in rats: persistent and independent traces of stimulus and reward location. PLoS One 6:e16462. CrossRef Medline

Itskov PM, Vinnik E, Honey C, Schnupp J, Diamond ME (2012) Sound sensitivity of neurons in rat hippocampus during performance of a sound-guided task. J Neurophysiol 107:1822-1834. CrossRef Medline

Jadhav SP, Kemere C, German PW, Frank LM (2012) Awake hippocampal sharp-wave ripples support spatial memory. Science 336:1454-1458. CrossRef Medline

Johnson A, Redish AD (2007) Neural ensembles in CA3 transiently encode paths forward of the animal at a decision point. J Neurosci 27:1217612189. CrossRef Medline

Kalm K, Davis MH, Norris D (2013) Individual sequence representations in the medial temporal lobe. J Cogn Neurosci 25:1111-1121. CrossRef Medline

Killian NJ, Jutras MJ, Buffalo EA (2012) A map of visual space in the primate entorhinal cortex. Nature 491:761-764. CrossRef Medline

Kjelstrup KB, Solstad T, Brun VH, Hafting T, Leutgeb S, Witter MP, Moser EI, Moser MB (2008) Finite scale of spatial representation in the hippocampus. Science 321:140-143. CrossRef Medline

Komorowski RW, Manns JR, Eichenbaum H (2009) Robust conjunctive item-place coding by hippocampal neurons parallels learning what happens where. J Neurosci 29:9918-9929. CrossRef Medline

Komorowski RW, Garcia CG, Wilson A, Hattori S, Howard, MW, Eichenbaum, H (2013) Ventral hippocampal neurons are shaped by experience to represent behaviorally relevant contexts. J Neurosci 33:8079-8087. CrossRef Medline

Kraus BJ, Robinson RJ 2nd, White JA, Eichenbaum H, Hasselmo ME (2013) Hippocampal "time cells": time versus path integration. Neuron 78: 1090-1101. CrossRef Medline

Libby LA, Hannula DE, Ranganath C (2014) Medial temporal lobe coding of item and spatial information during relational binding in working memory. J Neurosci 34:14233-14242. CrossRef Medline

Maguire EA, Mullally SL (2013) The hippocampus: a manifesto for change. J Exp Psychol Gen 142:1180-1189. CrossRef Medline

Maguire EA, Gadian DG, Johnsrude IS, Good CD, Ashburner J, Frackowiak RS, Frith CD (2000) Navigation-related structural change in the hippocampi of taxi drivers. Proc Natl Acad Sci U S A 97:43984403. CrossRef Medline

Mankin EA, Sparks FT, Slayyeh B, Sutherland RJ, Leutgeb S, Leutgeb JK (2012) Neuronal code for extended time in the hippocampus. Proc Natl Acad Sci U S A 109:19462-19467. CrossRef Medline

Mankin EA, Diehl GW, Sparks FT, Leutgeb S, Leutgeb JK (2015) Hippocampal CA2 activity patterns change over time to a larger extent than between spatial contexts. Neuron 85:190-201. CrossRef Medline

Manns J, Eichenbaum H (2009) A cognitive map for object memory in the hippocampus. Learn Mem 16:616-624. CrossRef Medline

Manns JR, Howard MW, Eichenbaum H (2007) Gradual changes in hippocampal activity support remembering the order of events. Neuron 56 : 530-540. CrossRef Medline

McKenzie S, Frank AJ, Kinsky NR, Porter B, Rivière PD, Eichenbaum H (2014) Hippocampal representation of related and opposing memories develop within distinct, hierarchically organized neural schemas. Neuron 83:202-215. CrossRef Medline

Milivojevic B, Doeller CF (2013) Mnemonic networks in the hippocampal formation: from spatial maps to temporal and conceptual codes. J Exp Psychol Gen 142:1231-1241. CrossRef Medline

Milivojevic B, Vicente-Grabovetsky A, Doeller CF (2015) Insight reconfigures hippocampal-prefrontal memories. Curr Biol 25:821-830. CrossRef Medline

Miller JF, Neufang M, Solway A, Brandt A, Trippel M, Mader I, Hefft S, Merkow M, Polyn SM, Jacobs J, Kahana MJ, Schulze-Bonhage A (2013) Neural activity in human hippocampal formation reveals the spatial context of retrieved memories. Science 342:1111-1114. CrossRef Medline

Moita MA, Rosis S, Zhou Y, LeDoux JE, Blair HT (2003) Hippocampal place cells acquire location-specific responses to the conditioned stimulus during auditory fear conditioning. Neuron 37:485-497. CrossRef Medline

Moser EI, Kropff E, Moser MB (2008) Place cells, grid cells, and the brain's spatial representation system. Annu Rev Neurosci 31:69-89. CrossRef Medline

Nadel L, Hoscheidt S, Ryan LR (2013) Spatial cognition and the hippocampus: the anterior-posterior axis. J Cogn Neurosci 25:22-28. CrossRef Medline

Naya Y, Suzuki WA (2011) Integrating what and when across the primate medial temporal lobe. Science 333:773-776. CrossRef Medline

Nielson DM, Smith TA, Sreekumar V, Dennis S, Sederberg PB (2015) Human hippocampus represents space and time during retrieval of realworld memories. Proc Natl Acad Sci U S A 112:11078-11083. CrossRef Medline

Nokia MS, Mikkonen JE, Penttonen M, Wikgren J (2012) Disrupting neural activity related to awake-state sharp wave-ripple complexes prevents hippocampal learning. Front Behav Neurosci 6:84. CrossRef Medline

O'Keefe J, Dostrovsky J (1971) The hippocampus as a spatial map. Preliminary evidence from unit activity in the freely-moving rat. Brain Res 34: 171-175. CrossRef Medline

O'Keefe J, Nadel L (1978) The hippocampus as a cognitive map. New York: Oxford UP.

Pastalkova E, Itskov V, Amarasingham A, Buzsáki G (2008) Internally generated cell assembly sequences in the rat hippocampus. Science 321:13221327. CrossRef Medline

Paz R, Gelbard-Sagiv H, Mukamel R, Harel M, Malach R, Fried I (2010) A neural substrate in the human hippocampus for linking successive events. Proc Natl Acad Sci U S A 107:6046-6051. CrossRef Medline

Pfeiffer BE, Foster DJ (2013) Hippocampal place-cell sequences depict future paths to remembered goals. Nature 497:74-79. CrossRef Medline

Piekema C, Kessels RP, Mars RB, Petersson KM, Fernández G (2006) The right hippocampus participates in short-term memory maintenance of object-location associations. Neuroimage 33:374-382. CrossRef Medline

Poch C, Fuentemilla L, Barnes GR, Düzel E (2011) Hippocampal thetaphase modulation of replay correlates with configural-relational shortterm memory performance. J Neurosci 31:7038-7042. CrossRef Medline

Poppenk J, Evensmoen HR, Moscovitch M, Nadel L (2013) Long-axis specialization of the human hippocampus. Trends Cogn Sci 17:230-240. CrossRef Medline

Ranganath C, Ritchey M (2012) Two cortical systems for memory-guided behaviour. Nat Rev Neurosci 13:713-726. CrossRef Medline

Robitsek RJ, White JA, Eichenbaum H (2013) Place cell activation predicts subsequent memory. Behav Brain Res 254:65-72. CrossRef Medline

Rolls ET, Xiang JZ (2006) Spatial view cells in the primate hippocampus and memory recall. Rev Neurosci 17:175-200. Medline

Schapiro AC, Kustner LV, Turk-Browne NB (2012) Shaping of object representations in the human medial temporal lobe based on temporal regularities. Curr Biol 22:1622-1627. CrossRef Medline

Scoville WB, Milner B (1957) Loss of recent memory after bilateral hippocampal lesions. J Neurol Neurosurg Psychiatry 20:11-21. CrossRef Medline

Shapiro ML, Kennedy PJ, Ferbinteanu J (2006) Representing episodes in the mammalian brain. Curr Opin Neurobiol 16:701-709. CrossRef Medline

Spiers HJ, Maguire EA (2006) Thoughts, behaviour, and brain dynamics during navigation in the real world. Neuroimage 31:1826-1840. CrossRef Medline

Staresina BP, Alink A, Kriegeskorte N, Henson RN (2013) Awake reactivation predicts memory in humans. Proc Natl Acad Sci U S A 110:21159_ 21164. CrossRef Medline

Strange BA, Witter MP, Lein ES, Moser EI (2014) Functional organization 
of the hippocampal longitudinal axis. Nat Rev Neurosci 15:655-669. CrossRef Medline

Tambini A, Ketz N, Davachi L (2010) Enhanced brain correlations during rest are related to memory for recent experiences. Neuron 65:280-290. CrossRef Medline

Tavares RM, Mendelsohn A, Grossman Y, Williams CH, Shapiro M, Trope Y, Schiller D (2015) A map for social navigation in the human brain. Neuron 87:231-243. CrossRef Medline

Teki S, Kumar S, von Kriegstein K, Stewart L, Lyness CR, Moore BC, Capleton B, Griffiths TD (2012) Navigating the auditory scene: an expert role for the hippocampus. J Neurosci 32:12251-12257. CrossRef Medline

Tolman EC (1948) Cognitive maps in rats and men. Psychol Rev 55:189208. CrossRef Medline

Tse D, Langston RF, Kakeyama M, Bethus I, Spooner PA, Wood ER, Witter MP, Morris RG (2007) Schemas and memory consolidation. Science 316:76-82. CrossRef Medline

Tulving E (1983) Elements of episodic memory. New York: Oxford UP.

Voss JL, Warren DE, Gonsalves BD, Federmeier KD, Tranel D, Cohen NJ

(2011) Spontaneous revisitation during visual exploration as a link among strategic behavior, learning, and the hippocampus. Proc Natl Acad Sci U S A 108:E402-E409. CrossRef Medline

Wang Y, Romani S, Lustig B, Leonardo A, Pastalkova E (2015) Theta sequences are essential for internally generated hippocampal firing fields. Nat Neurosci 18:282-288. CrossRef Medline

Watson PD, Voss JL, Warren DE, Tranel D, Cohen NJ (2013) Spatial reconstruction by patients with hippocampal damage is dominated by relational memory errors. Hippocampus 23:570-580. CrossRef Medline

Wood ER, Dudchenko PA, Robitsek RJ, Eichenbaum H (2000) Hippocampal neurons encode information about different types of memory episodes occurring in the same location. Neuron 27:623-633. CrossRef Medline

Woollett K, Maguire EA (2012) Exploring anterograde associative memory in London taxi drivers. Neuroreport 23:885-888. CrossRef Medline

Zeithamova D, Dominick AL, Preston AR (2012) Hippocampal and ventral medial prefrontal activation during retrieval-mediated learning supports novel inference. Neuron 75:168-179. CrossRef Medline 